\title{
Possession and Applicability of Signature Character Strengths: What Is Essential for Well-Being, Work Engagement, and Burnout?
}

\author{
Alexandra Huber, et al. [full author details at the end of the article]
}

Received: 6 October 2018 / Accepted: 28 November 2018/Published online: 13 January 2019

(C) The Author(s) 2019

\begin{abstract}
Signature character strengths can foster health-related outcomes in work and private life, thus being particularly important for endangered occupational groups like physicians. However, situational circumstances need to allow character strengths demonstration (applicability) first to enable their application. Therefore, this study addresses the role of (1) applicability of signature character strengths in work and private life beyond their possession and (2) relationships with well-being, work engagement, and burnout dimensions (emotional exhaustion, depersonalization, and reduced personal accomplishment). Hospital physicians $(N=274)$ completed an online survey examining their signature character strengths and applicability, well-being, work engagement, and burnout dimensions. The top-five individual signature character strengths were fairness, honesty, judgment, kindness, and love. Hierarchical multiple linear regressions revealed that the possession as well as the applicability of signature character strengths was important in work and private life, but to different degrees. Possessing fairness, honesty, or kindness indicated significant positive relations with subjective well-being, whereas judgment and kindness seemed to negatively interact with reduced personal accomplishment. Hospital physicians' applicability of fairness, honesty, judgment, and love was particularly essential for their psychological well-being and work engagement, whereas the applicability of fairness (reduced personal accomplishment) and judgment (emotional exhaustion, depersonalization) at work interacted negatively with the respective outcomes. Therefore, creating awareness for individual signature character strengths as well as providing applicability in hospitals and private life could be a promising approach to improve physicians' well-being and consequently patient care as well as the performance of the health-care system in general.
\end{abstract}

Keywords Signature character strengths · Applicability · Physicians · Well-being · Work engagement · Burnout

\section{Introduction}

The research area of positive psychology emerged in the late 1990s and deals with factors that make life most worth living to fulfill individual potentials by fostering 
human functioning (Seligman and Csikszentmihalyi 2000). In positive psychology three main scopes are relevant: a) positive subjective experiences (e.g., happiness/ satisfaction), b) positive individual traits (e.g., character strengths), and c) positive institutions (e.g., families/workplaces; Peterson 2006; Seligman and Csikszentmihalyi 2000). Beside the importance of possessing character strengths, their demonstration needs to be allowed or called (applicability) in particular by positive institutions to enable application in various life domains and foster deepened positive experiences (Govindji and Linley 2007; Peterson 2006; Rath 2007). Therefore, this analysis addresses the role of applicability of character strengths in work and private life beyond their possession and relationships with well-being, work engagement, and burnout.

\section{Character Strengths}

Peterson and Seligman (2004) introduced the Values in Action (VIA) classification to describe the good human character, representing 24 character strengths assigned to six different virtues (courage, humanity, justice, temperance, transcendence, wisdom) which have been theoretically considered important across many religions and cultures, going back to the Noble Eightfold Path (Buddhism, fifth century B.C.) and the Ten Commandments (first century B.C.). Character strengths are conceptualized as positive, stable and moral traits and their possession can be measured with the VIA-Inventory of Strengths (VIA-IS; Peterson and Park 2009; Peterson and Seligman 2004). Possession here means to have character strengths at least to a certain degree (see Harzer and Ruch 2013). Moreover, Peterson and Seligman claimed that everybody has about three to seven character strengths which are typical of an individual, akin to what Allport identified 1961 as personal traits (see Peterson and Seligman 2004), the so-called 'signature character strengths'. When people own, celebrate and frequently apply them, they are related to e.g., feelings of authenticity ('this is the real me') and excitement while displaying, people yearn to act in accordance with the strength, continuously learn new ways to enact the strength, and feel intrinsically motivated to apply them (Peterson and Seligman 2004). Therefore, they support peoples' accomplishment or engagement (e.g., creation and pursuit of projects that revolve around the strength) and positive emotions (e.g., invigoration rather than exhaustion when applying strengths). But to be able to apply these individual (signature) character strengths and show traitrelated behavior, situational circumstances in work or private life need to be conducive (Saucier et al. 2007) or in other words, offer applicability. Therefore, the 'Applicability of Character Strengths Rating Scales' (ACS-RS) aim to measure the extent to which each of the 24 character strengths of the VIA-IS is applicable (e.g., 'demanded', 'helpful' or 'important') in work and private life (Harzer and Ruch 2013).

Theoretical research perspectives have focused on both, possessing and applying character strengths. Empirically, studies have tended to concentrate more on their possession to a certain degree than on their applicability or application (e.g., Park et al. 2004; Peterson et al. 2007) whereas preliminary evidence indicated that particularly the latter substantially contributes to well-being (Gander et al. 2013; Govindji and Linley 2007; Rath 2007). This augmented focus on the possession of character strengths might be due to the late absence of psychometrically adequate scales (e.g., Harzer and Ruch 2013; Littman-Ovadia and Steger 2010) or to the circumstance that the VIA-IS measures possession of character strengths with items already including 
behavior patterns and applicability/application to some extent (e.g., 'When the topic calls for it, I can be a highly rational thinker', 'Everyone's rights are equally important to me', 'I really enjoy doing small favors for friends') making it even harder to exactly differentiate between possessing or applying character strengths.

\section{Positive Experiences in Private and Work Life}

\section{Well-Being}

Research on well-being can be differentiated in two traditions (Deci and Ryan 2008). In the hedonistic tradition the focus is on happiness, generally defined by life satisfaction, the presence of positive and the absence of negative affect (subjective well-being; Diener 1984) concerning different life domains (work, family, leisure, health, finances, self, and one's group; Diener et al. 1999). In the eudaimonic tradition the focus is on living one's life in a deeply satisfying way and countering existential challenges in daily life (psychological well-being) concerning aspects like autonomy, engagement, mastery, meaning, optimism, and relationships (e.g., Su et al. 2014). Although concepts of subjective and psychological well-being are related and interdependent, they are empirically distinct (Ring et al. 2007).

The 24 VIA-character strengths have been repeatedly analyzed in relation to well-being outcomes. The most strongly related character strengths to life satisfaction (as being part of subjective well-being) were curiosity $(r=.38-.39)$, gratitude $(r=.37-.43)$, hope $(r=.53-.59)$, love $(r=.44-.46)$, and zest $(r=.45-.53$; e.g., Buschor et al. 2013; Harzer 2016; Park et al. 2004) as well as to subjective well-being in total (curiosity: $r=.39$ to hope: $r=.67$; Hausler et al. 2017a). These character strengths are the so-called 'happiness strengths'. The application of e.g., hope and zest predicted subjective well-being in two UK student samples and correlated positively with self-esteem (Proctor et al. 2011) and positive affect (Ouweneel et al. 2014). Concerning psychological well-being there is less research, but first results suggested that possessing happiness strengths is important as well (love: $r=.38$ to hope: $r=.59$; Hausler et al. 2017a). Moreover, its aspects seem to be related to specific character strengths $(r \geq .40)$ : autonomy to bravery, curiosity, honesty, hope, perspective, and zest; engagement to curiosity, gratitude, humor, perseverance, and zest; mastery to creativity, curiosity, fairness, honesty, hope, perseverance, and zest; meaning to bravery, curiosity, gratitude, hope, leadership, love, perspective, spirituality, and zest; optimism to hope and zest; relationships to hope, love, social intelligence, and zest (Harzer 2016; Hausler et al. 2017a; Peterson et al. 2007). Overall, more subjective/psychological wellbeing can be achieved by (more frequently) applying character strengths (e.g., Allan and Duffy 2014; Douglass and Duffy 2014; Gander et al. 2013; Lyubomirsky et al. 2005; Proyer et al. 2014; Seligman et al. 2005).

\section{Work Engagement and Burnout}

Task- and organization-related working conditions (e.g., demands, resources, and stressors) can affect employees' healthiness, well-being, and motivation. Their outcomes (e.g., work engagement, burnout) can occur simultaneously in positive or negative ways (Glaser and Seubert 2014; Schaufeli et al. 2009). In particular, work engagement can contribute positively to occupational well-being (besides job motivation, organizational commitment, 
and work satisfaction) and is defined as positive, fulfilling work-related motivational state of mind characterized by vigor, dedication, and absorption (Schaufeli et al. 2002). It is inspired by positive psychology and characterizes a view on work-related well-being that takes personality- and health-promoting effects of work into account (Schaufeli et al. 2002), conceptualized as positive counterpart of job burnout. Burnout is usually defined as a syndrome comprising three dimensions: emotional exhaustion (depleted emotional and internal resources, feelings to not have anything more to give to the job), depersonalization (attempt to distance oneself from the job, feelings of increasing cynicism about the value of work, actively starting to ignore positive aspects of the job), and reduced personal accomplishment (feelings of much less effectiveness in the job, performance decreases; Maslach et al. 2001). Emotional exhaustion is strongly related to physical health outcomes (e.g., diabetes, infections, and cardiovascular diseases) and mental illness (Shirom et al. 2005) as well as high depersonalization (Leiter and Maslach 2016). However, the absence of burnout symptoms does not automatically mean that a person is engaged in work tasks.

First results indicated that the possession of happiness strengths is related to occupational well-being across a range of different professions (e.g., love: increased job satisfaction with work that explicitly involves other people; zest: work as calling; Peterson and Park 2006; Peterson et al. 2007). Moreover, the application of character strengths at work is related to various positive experiences (e.g., pleasure, work engagement, meaning) and job satisfaction (Harzer and Ruch 2012, 2013; Littman-Ovadia and Steger 2010; Peterson and Park 2011; Seligman 2011) as well as behavioral outcomes (e.g., perseverance; Littman-Ovadia and Lavy 2016). Littman-Ovadia et al. (2017) described in a study, distinguishing between signature character strengths and happiness strengths, that using the former contributed more to behavioral outcomes (job performance $r=.23$, organizational citizenship behavior $r=.38$, and counterproductive work behavior $r=-.22$ ) whereas happiness strengths were more related to psycho-emotional outcomes (work engagement $r=.65$, job satisfaction $r=.54$, and meaningfulness $r=.59$ ). Moreover, one study revealed the effect of work engagement mediating the relation of character strengths application and productivity, organizational citizenship behavior, and job satisfaction (Lavy and Littman-Ovadia 2017). Concerning burnout, one study examined work-related patterns and revealed that the resigned type (burnout working behavior; positively associated with the burnout dimensions) scored significantly lower in all character strengths than the healthy-ambitious type (actively coping, experiencing social support, being able to keep emotional distance from work, and to be satisfied with work and life in general); particularly large effect sizes were found in terms of hope, perseverance, and zest $\left(\eta^{2}=.40-.50\right.$; Gander et al. 2012). Significant indirect effects via emotional exhaustion (being one key dimension of burnout according to Maslach et al. 2001) were found recently concerning the link: 'applicability of character strengths' to 'subjective/psychological well-being, mental and physical health' in medical students $\left(\beta_{\text {indirect }}=.05-.15\right)$ and resident physicians (excl. Mental health, $\beta_{\text {indirect }}=.05-.09$; Hausler et al. 2017b).

\section{Physicians in Positive Institutions?}

Physicians belong to an endangered occupational group exposed to tremendous work demands and stressors (e.g., workload, time pressure, emotional interactions, cognitive demands) and when they feel unwell, the performance of health-care systems as well as 
patient care can be impaired (e.g., Wallace et al. 2009). A Canadian study revealed that $64 \%$ of physicians feel that their workload is too heavy and $48 \%$ experienced an increased workload in the past year leading to more absenteeism, job turnover, and earlier retirement (Canadian Medical Association 2003). When physicians frequently have work shifts lasting longer than $24 \mathrm{~h}$, the resulting fatigue is associated with negative personal and professional consequences: they have an increased burnout risk (resident physicians 60\%; physicians 51\%; Dyrbye et al. 2014), report significantly more failures of attention, and serious medical errors than those with shorter shifts (Landrigan et al. 2004; Lockley et al. 2004). Depression, substance abuse (antipsychotics, benzodiazepines, barbiturates), and suicide occurred as well above-average in physicians compared to the general population (Gold et al. 2013). Burnout and depression had a particular effect on medical errors (two to three times increased probability of reporting an error at least monthly or weekly) and moreover, rapid and recent changes to the practice of medicine (e.g., increased patient-care demands, wages, growing bureaucracy, and accountability) seem to be potential threats to physicians' well-being (Wallace et al. 2009). In Germany and Austria researchers found similar prevalences of burnout (up to 50\%) and depression (10\%) in local physicians (Heinke et al. 2011; Weigl et al. 2012; Wurm et al. 2016) corresponding to international findings. Therefore, it is questionable to what extent hospitals are positive institutions which allow or call for the demonstration of character strengths.

\section{Aims of this Analysis}

According to research so far, empirical evidence is lacking whether fostering applicability of character strengths in hospitals could be a promising approach to improve physicians' well-being. The medical occupation itself is already challenging and when working in conditions as outlined above, approaches to foster physicians' resources such as investigations of character strengths deployment are needed. Therefore, two aims emerged. (1) As the VIA-IS measures the possession of character strengths with items already including some behavior patterns and applicability/application, this questionnaire was compared with the ACS-RS to test if the two instruments measure theoretically distinct constructs or not. If results indicate diversity, (2) the applicability of signature character strengths in work and private life will be examined in terms of whether there is a potential to increase well-being and work engagement and prevent burnout of hospital physicians beyond the possession of signature character strengths. Therefore, the five most frequently reported individual signature character strengths will be examined.

\section{Methods}

\section{Sample and Procedure}

The study was conducted in two hospitals of a regional network including a large university hospital in Austria from 2015 to 2017. After ethic commission and institutional review board approval was given, hospital physicians completed an online survey. Offered incentives were vouchers (10 vouchers for a brunch at 50 Euros each) 
in a raffle. Data collection was part of a larger research project on health and well-being of medical students and hospital physicians funded by the Austrian Science Fund. A total of $N=274$ physicians participated. About $62 \%$ of participants were female, about $38 \%$ were male. The mean age was 34.2 years $(\mathrm{SD}=8.1$, range $=24-64$ years). A large majority of $N=215(78.5 \%)$ were resident physicians in training, $N=59(21.5 \%)$ were senior medical specialists. The physicians worked in 14 different medical disciplines.

\section{Measures}

\section{Character Strengths}

For measuring individual character strengths, the German 120-item version of the VIAIS (VIA-120) was used (Höfer et al. 2018, in this special issue; Littman-Ovadia 2015; original: VIA Institute on Character 2014). Psychometric properties were similar to the 240 -items version with Cronbach's alpha ranging in this sample from teamwork $\alpha=.61$ to spirituality $\alpha=.90$. The response format was a five-point scale from 'strongly agree' (=5) to 'strongly disagree' (=1). Item examples are: 'I always keep my promises' (honesty); 'I am never too busy to help a friend' (kindness); 'I am always willing to take risks to establish a relationship' (love).

\section{Applicability of Character Strengths}

The 'Applicability of Character Strengths Rating Scales' (ACS-RS; Harzer and Ruch 2013) were applied to evaluate the applicability of the five highest individual character strengths identified with the VIA-120 (also called signature character strengths according to Peterson and Seligman 2004) in regard to work and private life. For each of the top five individual signature character strength eight items (four questions referring to work and personal life each) were rated on a five-point scale from 'never' (=1) to '(almost) always' (=5). The ACS-RS focus on the individual perception of four influences: two external (normative demands and appropriateness of strength-related behavior) and two internal (perceived presence of factors that may facilitate or restrain strength-related behavior and intrinsic motivation to show certain behavior; Harzer and Ruch 2013). Therefore, the items ask if the character strength is 'demanded', 'helpful', 'important for me', and 'used' in work or private life. The internal consistencies in this sample ranged from $\alpha=.80$ to $\alpha=.89$.

\section{Well-Being}

The German version of the 'Comprehensive Inventory of Thriving' (CIT; Hausler et al. 2017; original: Su et al. 2014) was used to measure different aspects of well-being. It comprises 54 items rated on a five-point scale ranging from 'strongly disagree' $(=1)$ to 'strongly agree' (= 5). The items measure 18 aspects of well-being, three assigned to subjective well-being (SWB) and fifteen to psychological well-being (PWB) as composite scores (see Hausler et al. 2017). SWB comprises life satisfaction, positive and negative emotions; PWB includes autonomy, engagement, mastery (accomplishment, learning, self-efficacy, self-worth, and skills), meaning, optimism and relationships (belonging, community, loneliness, respect, support, and trust). Each aspect is 
measured with three items. A general well-being mean score including all SWB and PWB aspects can be calculated as well. Cronbach's $\alpha$ in this sample was .95 for SWB and .92 for PWB. Item examples are: 'My life is going well' (SWB; life satisfaction); 'There are people I can depend on to help me' (PWB; relationship).

\section{Work Engagement}

Work engagement was measured with the German nine-item short-version of the 'Utrecht Work Engagement Scale' (UWES; Schaufeli and Bakker 2003; Schaufeli et al. 2006) which is defined as a positive, fulfilling work-related state of mind that is characterized by vigor, dedication, and absorption (Schaufeli et al. 2006). The response format was a seven-point scale ranging from 'never' $(=0)$ to 'always' $(=6)$. Cronbach's $\alpha$ in the present study was .94. An item example is: 'At my job, I feel strong and vigorous'.

\section{Burnout}

For measuring the three dimensions of burnout, the adapted and modified German version of the 'Maslach-Burnout-Inventory' (MBI-D; Büssing and Perrar 1992) was used. It consists of 21 items comprising the three dimensions of emotional exhaustion (nine items), depersonalization (five items) and reduced personal accomplishment (seven items). They can be answered on a six-point scale from 'never' $(=0)$ to 'very often' (= 5). Satisfactory Cronbach's $\alpha$ in this sample were found, ranging from .70 (depersonalization) to .91 (emotional exhaustion). Item examples are: 'I feel emotionally drained from my work'; 'I don't really care what happens to some patients'; 'I have accomplished many worthwhile things in this job'.

\section{Statistical Analyses}

For all statistical analyses IBM SPSS Statistics 24 (IBM Corp. 2015) was used. Means \pm standard deviation, minimum/maximum scores, skew, kurtosis and scale reliabilities were calculated to describe the metric properties of the items and the scales. Pearson's coefficient inter-correlations were computed to assess the relationships of the study variables which can be interpreted as follows: $r<.10=$ no correlation, $r=.10-.29=$ low correlation, $r=.30-.49=$ moderate correlation, $r \geq .50=$ high correlation (Cohen 1988). Cronbach's $\alpha$ indicates acceptable internal consistency when values are $>.70$ (Nunnally 1978; see Peterson 1994). A priori G*power analyses were conducted, revealing a minimum of $N=74$ to be powerful (one-tailed, alpha-error .05, statistical power .95 , min. effect size 0.15; Faul et al. 2009). Hierarchical multiple linear regressions were performed (first step: VIA-120 signature character strength, method: enter; second step: applicability of signature character strengths in work (ASCS-W) and private life (ASCS-P), method: enter) to examine if respective applicabilities explained variance above and beyond the possession of the signature character strength. Their possession in model 1 and additionally their applicability in model 2 were the independent variables and subjective/psychological well-being, work engagement, and burnout (emotional exhaustion, depersonalization, reduced personal accomplishment) the dependent variables. ASCS-W was analyzed in all regressions (in regard to all outcomes), whereas ASCS-P was only analyzed in the regressions concerning SWB and PWB. 


\section{Results}

Descriptive statistics for all study variables including mean $\pm \mathrm{SD}$, min./max. scores, skew, kurtosis, and Cronbach's $\alpha$ are presented in Table 1, ranging from $\alpha=.61$ (teamwork) to $\alpha=.95$ (subjective well-being). First, we identified the five most frequently reported individual signature character strengths in the whole sample being honesty $(N=144)$, followed by kindness $(N=137)$, love $(N=132)$, judgment $(N=$ $131)$, and fairness $(N=92)$. The five character strengths most seldom among physicians' individual signature character strengths were spirituality $(N=11)$, perspective $(N=14)$, self-regulation $(N=16)$, prudence $(N=18)$, and leadership $(N=20)$. Means of all character strengths (VIA-120: $1-5)$ ranged from spirituality $(2.33 \pm 0.95)$ to honesty $(4.21 \pm 0.44)$. Out of the five signature character strength applicability scores (ACS-RS: $1-5)$ love had both the lowest and highest rating at work $(3.57 \pm 0.91)$ and in private life $(4.42 \pm 0.68)$. Definitions of the most frequently reported signature character strengths of the sample can be found in the appendix (Table 5). In terms of wellbeing (CIT: 1-5) and work engagement (UWES: 0-6) means ranged roughly in the upper third $(3.91 \pm 0.70 / 3.84 \pm 0.40 ; 3.66 \pm 1.09)$, regarding burnout (MBI-D: $0-5)$ in the lower half (from $1.31 \pm 0.50$ to $2.36 \pm 0.96$ ).

According to the first aim of this analysis, Pearson's coefficient inter-correlations between all relevant study variables (Table 2) suggested that the questionnaires VIA120 and ACS-RS measure empirically distinct constructs, namely the possession and applicability of the signature character strengths honesty, kindness, love, judgment, and fairness in this sample. The highest correlation was found between the signature character strength love and its applicability in private life $(r=.48)$, sharing about $23 \%$ of variance. Moreover, the inter-correlations between the scales of ASCS-P and ASCS-W were only low to moderate (from kindness $r=.39$ to judgment $r=.23$ ), sharing a maximum of about $15 \%$ variance, or even none (love $r=.01$ ).

According to the second aim, hierarchical multiple linear regressions revealed that the applicability of signature character strengths (ASCS) explained variance of the respective outcomes above and beyond their possession, but in different ways or to a different extent in the tested models. In the first step (model 1), each signature character strength was entered separately to test the weight of their possession relating to the outcome. In the second step (model 2), the respective applicability at work (ASCS-W) and in private life (ASCS-P) was entered as well to test if and how this impacts the weight of the possession revealed before (e.g., decrease, increase, or mediation) concerning the outcomes.

(a) The ASCS explained no variance of subjective well-being (SWB) above and beyond the possession of signature character strengths $\left(R^{2}\right.$-changes; Table 3$)$. The possession of fairness, honesty, and kindness was significantly related to SWB in both models, whereas the regression testing love led to an overall significant model 2, with neither possession nor applicability being significant on its own ( $p$ total). However, in model 2 the applicability of judgment in private life mediated the relation of the signature character strength judgment on SWB, exceeding the significant $\beta$-coefficient from model 1 (Table 3).

(b) The ASCS explained variance of psychological well-being (PWB) above and beyond the possession of fairness, honesty, judgment, and love $\left(R^{2}\right.$-changes; 
Table 1 Descriptives and Cronbach's $\alpha$ for all study variables $(N=274)$

\begin{tabular}{llll}
\hline $\operatorname{mean}(\mathrm{SD})$ & $\min . \mid \max$. & skew $\mid$ kurtosis & $\alpha$ \\
\hline
\end{tabular}

VIA-120

(1) Wisdom and knowledge

Creativity

Curiosity

Judgment

Love of learning

Perspective

(2) Courage

Bravery
Honesty
Perseverance
Zest

(3) Humanity

Kindness
Love
Social intelligence

(4) Justice

Fairness
Leadership
Teamwork

(5) Temperance

Forgiveness
Humility
Prudence
Self-regulation

(6) Transcendence

Appreciation of beauty \& excellence
Gratitude
Hope

Humor

Spirituality

ASCS-W (Top 5)

Fairness
Honesty
Judgment
Kindness
Love

ASCS-P (Top 5)

Fairness

Honesty

Judgment

$\begin{array}{llll}3.45(.69) & 1.00 \mid 5.00 & -0.25 \mid 0.35 & .85 \\ 3.84(.55) & 2.20 \mid 5.00 & -0.37 \mid 0.06 & .72 \\ 4.00(.51) & 2.20 \mid 5.00 & -0.20 \mid-0.09 & .73 \\ 3.64(.68) & 1.60 \mid 5.00 & -0.09 \mid-0.29 & .76 \\ 3.37(.53) & 2.00 \mid 5.00 & 0.06 \mid 0.21 & .65\end{array}$

$\begin{array}{llll}3.43(.63) & 1.20 \mid 5.00 & -0.15 \mid 0.10 & .74 \\ 4.21(.44) & 2.80 \mid 5.00 & -0.27 \mid-0.20 & .62 \\ 3.93(.58) & 2.00 \mid 5.00 & -0.55 \mid 0.48 & .75 \\ 3.49(.65) & 1.80 \mid 5.00 & -0.21 \mid-0.25 & .78\end{array}$

$\begin{array}{llll}4.10(.50) & 2.80 \mid 5.00 & -0.18 \mid-0.27 & .73 \\ 4.03(.67) & 1.60 \mid 5.00 & -0.82 \mid 0.90 & .78 \\ 3.89(.52) & 2.40 \mid 5.00 & -0.30 \mid-0.08 & .70\end{array}$

$\begin{array}{llll}4.03(.55) & 2.00 \mid 5.00 & -0.68 \mid 0.61 & .73 \\ 3.66(.53) & 2.00 \mid 5.00 & 0.06 \mid-0.05 & .66 \\ 3.71(.50) & 2.00 \mid 5.00 & -0.31 \mid 0.54 & .61\end{array}$

$\begin{array}{llll}3.44(.63) & 1.80 \mid 5.00 & -0.05 \mid-0.20 & .66 \\ 3.29(.63) & 1.40 \mid 4.80 & -0.10 \mid 0.01 & .69 \\ 3.49(.60) & 1.80 \mid 4.80 & -0.16 \mid-0.24 & .71 \\ 3.15(.69) & 1.20 \mid 4.80 & -0.19 \mid-0.14 & .65\end{array}$

$\begin{array}{llll}3.51(.66) & 1.60 \mid 5.00 & -0.11 \mid-0.50 & .74 \\ 3.53(.62) & 1.80 \mid 5.00 & 0.07 \mid-0.25 & .77 \\ 3.71(.60) & 2.00 \mid 5.00 & -0.31 \mid-0.01 & .68 \\ 3.71(.68) & 2.00 \mid 5.00 & -0.11 \mid-0.37 & .82 \\ 2.33(.95) & 1.00 \mid 5.00 & 0.56 \mid-0.33 & .90\end{array}$

$4.00(.70) \quad 2.50|5.00 \quad-0.30|-0.69 \quad .75$

$3.96(.76) \quad 2.00|5.00 \quad-0.46|-0.45 \quad .80$

$4.04(.70) \quad 2.00|5.00 \quad-0.51| 0.14 \quad .75$

$\begin{array}{lll}4.07(.69) & 2.25 \mid 5.00 & -0.35 \mid-0.72 \quad .69\end{array}$

$3.57(.91) \quad 1.00|5.00 \quad-0.41|-0.27 \quad .83$

$\begin{array}{llll}4.26(.60) & 3.00 \mid 5.00 & -0.39 \mid-0.63 & .82 \\ 4.33(.65) & 2.00 \mid 5.00 & -0.96 \mid 0.83 & .86 \\ 4.17(.67) & 2.25 \mid 5.00 & -0.41 \mid-0.45 & .82\end{array}$


Table 1 (continued)

\begin{tabular}{|c|c|c|c|c|}
\hline & mean (SD) & $\min . \mid \max$. & skew $\mid$ kurtosis & $\alpha$ \\
\hline Kindness & $4.27(.68)$ & $2.00 \mid 5.00$ & $-0.93 \mid 0.76$ & .81 \\
\hline Love & $4.42(.68)$ & $2.00 \mid 5.00$ & $-1.30 \mid 1.45$ & .91 \\
\hline \multicolumn{5}{|l|}{ CIT } \\
\hline Subjective well-being & $3.91(.70)$ & 1.33 | 5.00 & $-0.83 \mid 0.89$ & .95 \\
\hline Psychological well-being & $3.84(.40)$ & $2.58 \mid 4.76$ & $-0.47 \mid 0.34$ & .92 \\
\hline \multicolumn{5}{|l|}{ UWES } \\
\hline Work Engagement & $3.66(1.09)$ & $.22 \mid 5.78$ & $-0.47 \mid-0.21$ & .94 \\
\hline \multicolumn{5}{|l|}{ MBI-D } \\
\hline Emotional exhaustion & $2.36(.96)$ & $.11 \mid 4.67$ & $0.44 \mid-0.17$ & .91 \\
\hline Depersonalization & $1.45(.78)$ & $.00 \mid 4.20$ & $0.32 \mid-0.33$ & .70 \\
\hline Reduced personal accomplishment & $1.31(.50)$ & $.00 \mid 3.00$ & $0.02 \mid 0.27$ & .73 \\
\hline
\end{tabular}

ASCS-P /-W = applicability of signature character strengths in private life/ at work, CIT $=$ Comprehensive Inventory of Thriving, MBI-D = Maslach Burnout Inventory-Deutsch, SD = standard deviation, UWES = Utrecht Work Engagement Scale, VIA-120 = Values in Action-Inventory of Strengths

Table 3). PWB was significantly related to the possession of all signature character strengths in both models, and to the applicability of fairness, honesty, judgment, and love in model 2. The applicability of honesty and love at work revealed similar $\beta$-coefficients compared to the possession $\beta$-coefficients in model 2 , whereas different weights were found concerning the applicability in private life of fairness (applicability: $\beta=.24$; possession: $\beta=.44$ ) and judgment (applicability: $\beta=.37$; possession: $\beta=.30$ ). The applicability of kindness at work or in private life seemed not to be relevant for PWB in this sample.

(c) The ASCS explained variance of work engagement above and beyond the possession of fairness, honesty, judgment, and love ( $R^{2}$-changes; Table 4$)$. Concerning honesty and love, only their applicability at work resulted in the significant $\beta$ coefficients (model 2) and moreover, the applicability of both fairness and judgment at work mediated the relation of the signature character strength itself and work engagement, exceeding the significant $\beta$-coefficients from model 1 (Table 4 ).

(d) The applicability of judgment at work revealed significant $\beta$-coefficients in emotional exhaustion and depersonalization, therefore significantly explaining variance above and beyond the possession of judgment in model 2 ( $R^{2}$-changes; Table 4$)$. Reduced personal accomplishment was significantly related to the possession of judgment and kindness in both models, whereas the applicability of fairness at work mediated the relation of the signature character strength itself and reduced personal accomplishment, exceeding the significant $\beta$-coefficient from model 1 (Table 4).

\section{Discussion}

The analysis of Austrian hospital physicians revealed that the questionnaires VIA-120 and ACS-RS measure empirically distinct constructs concerning the possession and 


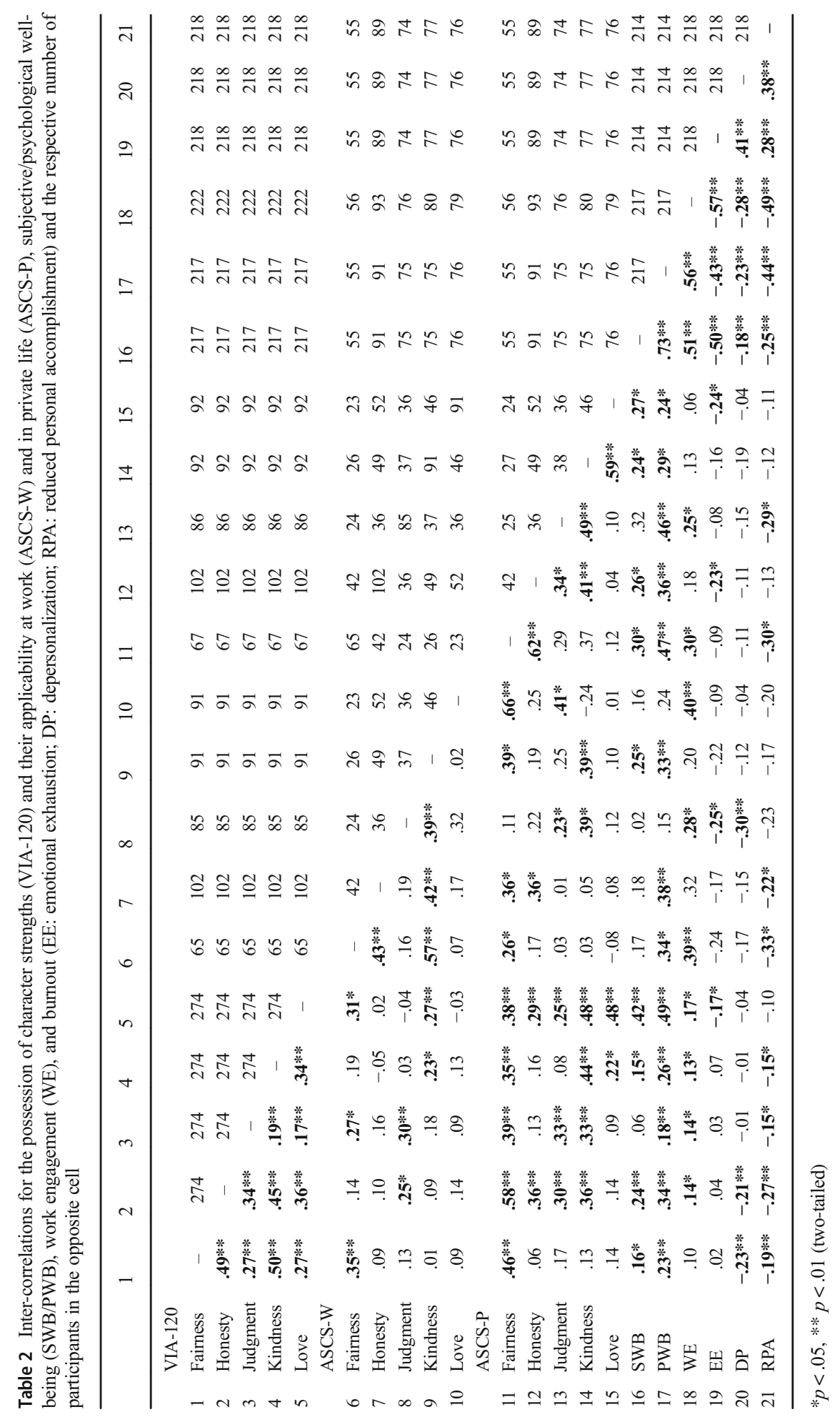


Table 3 Hierarchical multiple linear regressions including the applicability of signature character strengths in work (ASCS-W) and private life (ASCS-P) into the possession (VIA-120) and subjective/ psychological wellbeing (SWB / PWB) relation

\begin{tabular}{|c|c|c|c|c|c|c|c|c|}
\hline \multirow{2}{*}{ Outcome: SWE } & & \multicolumn{2}{|c|}{ Model 1} & \multicolumn{5}{|c|}{ Model 2} \\
\hline & & $R^{2}$ & $\beta$ & $R^{2}$ & $R^{2}$-Change & $\beta$ & $p$ total & $N$ \\
\hline \multirow[t]{3}{*}{ Fairness } & VIA-IS 120 & .205 & $.453 * *$ & .221 & .016 & $.390 * *$ & .005 & 91 \\
\hline & ASCS-W & & & & & .053 & & \\
\hline & ASCS-P & & & & & .118 & & \\
\hline \multirow[t]{3}{*}{ Honesty } & VIA-IS 120 & .093 & $.305^{* *}$ & .130 & .037 & $.251 *$ & .007 & 75 \\
\hline & ASCS-W & & & & & .102 & & \\
\hline & ASCS-P & & & & & .139 & & \\
\hline \multirow[t]{3}{*}{ Judgment } & VIA-IS 120 & .054 & $.232 *$ & .128 & .074 & .168 & .020 & 76 \\
\hline & ASCS-W & & & & & -.089 & & \\
\hline & ASCS-P & & & & & $.287 *$ & & \\
\hline \multirow[t]{3}{*}{ Kindness } & VIA-IS 120 & .105 & $.324 * *$ & .142 & .037 & $.260 *$ & .012 & 75 \\
\hline & ASCS-W & & & & & .164 & & \\
\hline & ASCS-P & & & & & .070 & & \\
\hline \multirow[t]{3}{*}{ Love } & VIA-IS 120 & .047 & .217 & .113 & .066 & .119 & .034 & 55 \\
\hline & ASCS-W & & & & & .177 & & \\
\hline & ASCS-P & & & & & .215 & & \\
\hline \multicolumn{9}{|c|}{ Outcome: PWB } \\
\hline \multirow[t]{3}{*}{ Fairness } & VIA-IS 120 & .344 & $.586 * * *$ & .438 & $.094 *$ & $.440 * * *$ & $<.001$ & 91 \\
\hline & ASCS-W & & & & & .188 & & \\
\hline & ASCS-P & & & & & $.243 *$ & & \\
\hline \multirow[t]{3}{*}{ Honesty } & VIA-IS 120 & .135 & $.368 * * *$ & .279 & $.143 * * *$ & $.288 * *$ & $<.001$ & 75 \\
\hline & ASCS-W & & & & & $.295 * *$ & & \\
\hline & ASCS-P & & & & & .166 & & \\
\hline \multirow[t]{3}{*}{ Judgment } & VIA-IS 120 & .162 & $.403 * * *$ & .286 & $.123 * *$ & $.295 * *$ & $<.001$ & 76 \\
\hline & ASCS-W & & & & & -.013 & & \\
\hline & ASCS-P & & & & & $.370 * *$ & & \\
\hline \multirow[t]{3}{*}{ Kindness } & VIA-IS 120 & .167 & $.408 * * *$ & .230 & .063 & $.329 * *$ & $<.001$ & 75 \\
\hline & ASCS-W & & & & & .227 & & \\
\hline & ASCS-P & & & & & .071 & & \\
\hline \multirow[t]{3}{*}{ Love } & VIA-IS 120 & .099 & $.314 * *$ & .177 & $.078 *$ & $.273 *$ & .003 & 55 \\
\hline & ASCS-W & & & & & $.263 *$ & & \\
\hline & ASCS-P & & & & & .111 & & \\
\hline
\end{tabular}

Notes: bold = significant; $p$-values for $\beta, R^{2}$-changes and total $=* \mathrm{p}<.05, * * \mathrm{p}<.01, * * * p<.001 ; p$ total values $=$ significance of model 2 in total (possession and applicability in work $\&$ private life taken into account), $\mathrm{N}=$ number of participants

applicability of the signature character strengths (ASCS) fairness, honesty, judgment, kindness, and love (shared variance $<24 \%$ ). All signature character strengths correlated significantly higher with applicability in private life (ASCS-P) than with applicability at 
Table 4 Hierarchical multiple linear regressions including the applicability of signature character strengths at work (ASCS-W) into the possession (VIA-120) and work engagement (WE), emotional exhaustion (EE), depersonalization (DP) and reduced personal accomplishment (RPA) relation

\begin{tabular}{|c|c|c|c|c|c|c|c|c|}
\hline \multirow{2}{*}{\multicolumn{2}{|c|}{ Outcome: WE }} & \multicolumn{2}{|c|}{ Model 1} & \multicolumn{5}{|c|}{ Model 2} \\
\hline & & \multirow{2}{*}{$\frac{R^{2}}{.105}$} & \multirow{2}{*}{$\frac{\beta}{.324^{*}}$} & \multirow{2}{*}{$\begin{array}{l}R^{2} \\
.213\end{array}$} & \multirow{2}{*}{$\frac{R^{2} \text {-Change }}{. \mathbf{1 0 8}^{* *}}$} & \multirow{2}{*}{$\frac{\beta}{.250}$} & \multirow{2}{*}{$\frac{p \text { total }}{\mathbf{. 0 0 2}}$} & \multirow{2}{*}{$\frac{N}{93}$} \\
\hline Fairness & $\begin{array}{l}\text { VIA-120 } \\
\text { ASCS-W }\end{array}$ & & & & & & & \\
\hline Honesty & $\begin{array}{l}\text { VIA-120 } \\
\text { ASCS-W }\end{array}$ & .020 & .142 & .120 & $.100 * *$ & $\begin{array}{l}.126 \\
.317 * *\end{array}$ & .003 & 80 \\
\hline Judgment & $\begin{array}{l}\text { VIA-120 } \\
\text { ASCS-W }\end{array}$ & .052 & $.229 *$ & .103 & $.051 *$ & $\begin{array}{l}.171 \\
.233 *\end{array}$ & .019 & 79 \\
\hline Kindness & $\begin{array}{l}\text { VIA-120 } \\
\text { ASCS-W }\end{array}$ & .043 & .208 & .069 & .026 & $\begin{array}{l}.173 \\
.164\end{array}$ & .064 & 76 \\
\hline Love & $\begin{array}{l}\text { VIA-120 } \\
\text { ASCS-W }\end{array}$ & $<.001$ & .009 & .163 & $.163 * * *$ & $\begin{array}{l}.034 \\
. \mathbf{4 0 4} * * *\end{array}$ & .001 & 56 \\
\hline Outcome: & & & & & & & & \\
\hline Fairness & $\begin{array}{l}\text { VIA-120 } \\
\text { ASCS-W }\end{array}$ & .003 & -.057 & .056 & .053 & $\begin{array}{l}-.004 \\
-.235\end{array}$ & .225 & 89 \\
\hline Honesty & $\begin{array}{l}\text { VIA-120 } \\
\text { ASCS-W }\end{array}$ & .001 & .032 & .029 & .028 & $\begin{array}{l}.044 \\
-.168\end{array}$ & .282 & 77 \\
\hline Judgment & $\begin{array}{l}\text { VIA-120 } \\
\text { ASCS-W }\end{array}$ & $<.001$ & .017 & .072 & $.072 *$ & $\begin{array}{l}.089 \\
-.277 *\end{array}$ & .071 & 76 \\
\hline Kindness & $\begin{array}{l}\text { VIA-120 } \\
\text { ASCS-W }\end{array}$ & $<.001$ & -.011 & .048 & .048 & $\begin{array}{l}.039 \\
-.224\end{array}$ & .163 & 74 \\
\hline Love & $\begin{array}{l}\text { VIA-120 } \\
\text { ASCS-W }\end{array}$ & .002 & -.048 & .010 & .008 & $\begin{array}{l}-.052 \\
-.089\end{array}$ & .688 & 55 \\
\hline Outcome: & & & & & & & & \\
\hline Fairness & $\begin{array}{l}\text { VIA-120 } \\
\text { ASCS-W }\end{array}$ & .001 & -.029 & .029 & .028 & $\begin{array}{l}.010 \\
-.173\end{array}$ & .464 & 89 \\
\hline Honesty & $\begin{array}{l}\text { VIA-120 } \\
\text { ASCS-W }\end{array}$ & .002 & -.042 & .024 & .022 & $\begin{array}{l}-.031 \\
-.148\end{array}$ & .358 & 77 \\
\hline Judgment & $\begin{array}{l}\text { VIA-120 } \\
\text { ASCS-W }\end{array}$ & .009 & -.095 & .089 & $.080 *$ & $\begin{array}{l}-.018 \\
-.293 *\end{array}$ & .037 & 76 \\
\hline Kindness & $\begin{array}{l}\text { VIA-120 } \\
\text { ASCS-W }\end{array}$ & .025 & -.159 & .033 & .008 & $\begin{array}{l}-.138 \\
-.093\end{array}$ & .284 & 74 \\
\hline Love & $\begin{array}{l}\text { VIA-120 } \\
\text { ASCS-W }\end{array}$ & .002 & .041 & .003 & .001 & $\begin{array}{l}.039 \\
-.036\end{array}$ & .898 & 55 \\
\hline Outcome: & & & & & & & & \\
\hline Fairness & $\begin{array}{l}\text { VIA-120 } \\
\text { ASCS-W }\end{array}$ & .079 & $-.281 *$ & .155 & $.077 *$ & $\begin{array}{l}-.217 \\
-.284 *\end{array}$ & .012 & 89 \\
\hline Honesty & $\begin{array}{l}\text { VIA-120 } \\
\text { ASCS-W }\end{array}$ & .026 & -.160 & .068 & .042 & $\begin{array}{l}-.146 \\
-.206\end{array}$ & .048 & 77 \\
\hline
\end{tabular}


Table 4 (continued)

\begin{tabular}{|c|c|c|c|c|c|c|c|c|}
\hline \multirow{2}{*}{\multicolumn{2}{|c|}{ Outcome: WE }} & \multicolumn{2}{|c|}{ Model 1} & \multicolumn{5}{|c|}{ Model 2} \\
\hline & & $R^{2}$ & $\beta$ & $R^{2}$ & $R^{2}$-Change & $\beta$ & $p$ total & $N$ \\
\hline \multirow[t]{2}{*}{ Judgment } & VIA-120 & .143 & $-.378 * *$ & .161 & .018 & $-.343 * *$ & .002 & 76 \\
\hline & ASCS-W & & & & & -.138 & & \\
\hline \multirow[t]{2}{*}{ Kindness } & VIA-120 & .104 & $-.322 * *$ & .115 & .011 & $-.298^{*}$ & .011 & 74 \\
\hline & ASCS-W & & & & & -.107 & & \\
\hline \multirow[t]{2}{*}{ Love } & VIA-120 & .006 & -.078 & .046 & .040 & -.089 & .178 & 55 \\
\hline & ASCS-W & & & & & -.201 & & \\
\hline
\end{tabular}

Notes: bold = significant; $p$-values for $\beta, R^{2}$-changes and total $=* \mathrm{p}<.05, * * \mathrm{p}<.01, * * * \mathrm{p}<.001 ; p$ total values $=$ significance of model 2 in total (possession and applicability in work life taken into account), $\mathrm{N}=$ number of participants

work (ASCS-W). Hierarchical multiple linear regressions revealed that the ASCS explained variance of the respective outcomes above and beyond the possession of signature character strengths, but only in about one third of the tested models significantly. The applicability of fairness, honesty, judgment, and love explained additional variance for PWB (work: honesty and love; private life: fairness and judgment) and work engagement. In particular at work, the applicability of judgment explained additional variance for emotional exhaustion and depersonalization, as well did the applicability of fairness for reduced personal accomplishment.

The literature on (signature) character strengths research implies that in general their application rather than possession contributes to well-being (Govindji and Linley 2007; Rath 2007) but there has been little discussion of their applicability in daily life so far (Harzer and Ruch 2013). The environment and circumstances in which the behavior of a person usually occurs (e.g., opportunity to demonstrate behavior due to situational factors) is crucial and the importance of contextual factors in positive psychology has already been acknowledged in the past (Seligman and Csikszentmihalyi 2000). With the ACS-RS, the extent to which character strengths are applicable at work or in private life (Harzer and Ruch 2013) can be measured and considered separately. As all of the five most frequently reported signature character strengths (fairness, honesty, judgment, kindness, and love) correlated higher with applicability in private life than with applicability at work, the assumption arises that the degree of possessing (one of these) character strengths is more decisive in the relation to private life than to work. So a higher degree of possession correlated with more perceived applicability in private life, whereas in work life e.g., the degree of possessing honesty and love did not correlate with the respective applicability at all. Therefore, it was not relevant if physicians had lower or higher honesty or love scores relating to their applicability rating at work. Physicians are exposed to tremendous work demands and stressors (e.g., lack of autonomy, organizational stressors, adverse working hours), therefore kept busy with occupational challenges and not experiencing high applicability of honesty or love. This was further supported by the lowest scores of applicability of honesty and love at work. But if they experienced applicability, an additional contribution to PWB and work engagement revealed. Overall, physicians evaluated the applicability of characters strengths in private life significantly higher and maybe due to this they can compensate 
'missing' applicability of character strengths at work. There could be other reasons as well as external factors which might have more or additional constraining influence on ASCS-W (e.g., no necessity or desirability at work, personal expectation to behave in a different way, restraining organizational structures).

External factors can also have a supporting effect, e.g., the socio-moral climate in an organization. It is characterized by discursive, participative, appreciative, supportive, and caring interactions between supervisors, subordinates, and co-workers (Pircher Verdorfer et al. 2012; Weber et al. 2008). As a social climate allows or even encourages employees to express their individual perspectives, opinions, and standpoints (independently of their rank or formal position), it is conceivable that it positively correlates with ASCS-W. In this regard first evidence has been given, even for a reciprocal relation (impact of socio-moral climate on the ASCS six months later, and an even stronger reversed effect; Höge et al. 2018, in this special issue). Other work characteristics like skill adequacy, cognitive (challenging) demands, or autonomy could also play an important role in terms of personality development (Glaser et al. 2015), further positively influencing ASCS-W. They could be seen as 'catalyzers' enabling individuals to apply their signature character strengths. The fit between a person and the work task (skill adequacy) would be a highly advisable example (e.g., Harzer and Ruch 2013). Otherwise the employee is concerned with excessive or unchallenging demands and may lose the ability to develop optimally. Cognitive demands and autonomy can further push intrinsic motivation and as individuals are primarily intrinsically motivated to apply their strengths (Linley et al. 2010) their existence at work must be considered in regard to their ASCS-W. A recent study revealed that these work characteristics in hospitals are significantly associated with physicians' ASCS (Strecker et al. 2018, in this special issue). Therefore, attempts to strengthen well-being at work by means of applying signature character strengths in the future should definitely take work characteristics into account, develop strategies to manage workload efficiently, and promote physicians' abilities to increase resources for successful coping.

The most frequently reported signature character strengths of the participating physicians in this sample (honesty, kindness, love, judgment, and fairness) differed in their patterns in regard to the respective outcomes. These different patterns might partially be explained by the definition of the character strengths themselves (see appendix Table 5), their required conditions for applicability as well as by the corresponding outcome. For example, possessing kindness was significantly related to SWB, PWB, and reduced personal accomplishment. Kindness can be numbered among the so-called 'tonic' strengths, being applicable in more situations than 'phasic' strengths, being relevant for specific situations only (Peterson and Seligman 2004). Therefore, high applicability might not be that crucial for being kind in work or private life across many situations, whereas judgment can rather be counted a 'phasic' strength, definitely requiring more applicability. This was supported by significant results of ASCS-P where perceived applicability seemed to be relevant for well-being (SWB/ PWB) and even more for work with situational factors calling for the demonstration of judgment (work engagement, emotional exhaustion, and depersonalization). Emotional exhaustion and depersonalization were in particular significantly negative related to the applicability of judgment at work. Therefore, having the time and opportunity to think critically, considering decisions carefully without mental pressure, and weighing all evidence fairly can protect physicians who possess the signature character strength 
against emotional exhaustion and depersonalization, being the two key dimensions of burnout (Leiter and Maslach 2016). Moreover, the applicability of fairness at work was significantly related to reduced personal accomplishment the same way, so that the possibility of treating all people the same and giving everyone a fair chance despite work demands or stressors seemed to strengthen perceived effectiveness in the hospital.

The absence of burnout symptoms does not automatically mean that a person is engaged in the work tasks. Although job burnout and work engagement are strongly negatively related, factor analytical results indicate that they are distinctive (Schaufeli et al. 2002). Moreover, outlining the Job-Demands-Resources-Model of Engagement and Burnout, Bakker and Demerouti (2007) argued that both constructs are triggered by different underlying processes. Burnout is predominantly caused by work demands (e.g., workload, work stressors) whereas work engagement is primarily fueled by taskrelated and personal resources (e.g., job control, autonomy, task variability, social support, or self-efficacy beliefs). As character strengths can be understood as personal resource, the importance of being applicable at work is evident. Therefore, perceived applicability of fairness, honesty, judgment, and love was essential for hospital physicians' work engagement and moreover, as well for their PWB (honesty and love at work, fairness and judgment in private life). Beside their applicability, their possession (including kindness) was important as well, suggesting that both constructs have a strong relationship to PWB, even stronger than to SWB (no tested model including the ASCS was significantly adding incremental variance). However, the applicability of judgment in private life mediated the relation of judgment and SWB ('phasic' strength) and possessing fairness, honesty, or kindness was an indicator for a significant positive relation with SWB. Previous results already suggested that the overall 'good character' (Hausler et al. 2017a) as well as the applicability at work (Hausler et al. 2017b) was significantly more closely related to PWB than to SWB. Therefore, one could interpret the existing results as supportive for the hypothesis of PWB and signature character strengths having a stronger reciprocal relationship already due to their respective definitions, in contrast to emotions and satisfaction in different life domains.

\section{Implications}

Based on the presented analysis, there is a difference between the possession and the applicability of fairness, honesty, judgment, kindness, and love at work and in private life. Further studies should take that into account together with the difference of tonic/ phasic strengths and the influence of setting variables (e.g., demands/stressors; sociomoral climate; fit between person and surrounding). Caution with labeling the constructs is encouraged whether it is a question of possessing or applying character strengths. Practically, creating awareness for individual signature character strengths as well as focusing on the setting variables to enhance the applicability in hospitals could be a starting point to improve physicians' well-being. This would be in line with the third pillar of positive psychology by developing positive institutions. Although diverse patterns were found, all of the signature character strengths added something to physicians' well-being. In particular the applicability of fairness and judgment took a mediating role substantiating further experimental research to explicitly test if more applicability of character strengths consistent with organizational structures has the potential to enhance physicians' well-being. Moreover, supervisors could be informed 
of their importance and trained to 'demand' for strengths or to evaluate them as 'helpful'. Honesty, love and kindness (and their applicability) could be fostered in terms of being 'important' in particular for jobs involving other people.

\section{Limitations and Future Research Suggestions}

Presented cross-sectional data are limited to results from one occupational group from two hospitals based upon subjective assessment only. Therefore, country-specific work structures, organizational procedures or personal requirements may have influenced the perception of applicability in a certain way to which signature character strengths are 'demanded', 'helpful', or 'important' in work life, raising the question how these ratings would look like in other hospitals. Moreover, all self-ratings could contain effects of self-representation or social desirability relating to the medical profession as well as other response biases. In particular when examining SWB, assimilation (valuative judgments towards the position of context stimuli) or contrast effects (negative correlation between a judgment and contextual information) can occur (Schwarz and Strack 1999). Moreover, the reduced sample size needs to be considered when interpreting the data concerning the signature character strength fairness. Finally, to give causal interpretations and generalized implications, longitudinal studies including more hospitals and peer-ratings with different organizational structures are needed, further including different cultures or behavioral/objective measures (e.g., social perception of signature character strengths from related party; observation of acting in real situations).

Furthermore, physicians only received feedback on their five highest ranked character strengths from the VIA-120 and so the ASC-RS were only answered for these respectively. As other patterns could occur regarding the applicability of other signature character strengths, future study designs might profit by analyzing the applicability of all character strengths in order to get a more profound understanding concerning different domains. The patterns discovered in this analysis are differing and therefore not directly transferable to other signature character strengths. Future research could also gain deeper insights when additionally analyzing more differentiated domains beside 'work' and 'private life' according to the various life domains in SWB to be considered (e.g., leisure, health, finances, one's group; Diener et al. 1999).

Beside the ASCS, other individual strengths focusing on e.g., occupational settings (Buckingham and Clifton 2001) or a comprehensive applicability at work and in various life domains (Linley and Harrington 2006) could significantly influence well-being, work engagement, and burnout positively as well. These concepts define strengths as natural capacities coming from within that one yearns to use, that enable authentic expression and that energize (Govindji and Linley 2007), and which belong to positive traits or psychological capacities/talents refined with knowledge and skills (Proctor et al. 2011). This definition comprises character strengths, but is not limited to them, therefore including e.g., sportiness, manual skills, cooking, health maintaining strategies, multicultural competence, peer resistance, perfectionism, ability to relax, amusement, organizational abilities, optimistic thinking, etc. Their application was positively related to well-being (e.g., Huber et al. 2017), but their applicability in terms of being 'demanded', 'helpful', or 'important' has not been analyzed explicitly. As the applicability seems to be an 
empirically distinct construct according to the results from this analysis, the ACS-RS items could be 'translated' into a future instrument examining the applicability of individual strengths in different domains.

\section{Conclusions}

Data led to the assumption that the possession as well as the applicability of signature character strengths (fairness, honesty, judgment, kindness, or love) at work and in private life was important, but to differing degrees. Possessing the signature character strengths of fairness, honesty, or kindness - but not their applicability - was an indicator for a significant positive relation with subjective well-being as well as only the possession of judgment and kindness seemed to interact negatively with reduced personal accomplishment. However, hospital physicians' applicability of signature character strengths fairness, honesty, judgment, and love was particularly essential for their psychological well-being and work engagement, more than their possession. Concerning the dimensions of burnout, only the applicability of judgment (emotional exhaustion, depersonalization) and fairness (reduced personal accomplishment) seemed to play a role. Overall, the analyses revealed diverse patterns for fairness, honesty, judgment, kindness, and love of Austrian hospital physicians, allowing first statements on their meaning.

Acknowledgements Open access funding provided by University of Innsbruck and Medical University of Innsbruck. This research is funded by the Austrian Science Fund (FWF) under project number P27228-G22. We express our gratitude to Mirjam Brenner, MSc, for her comprehensive support concerning the data administration and processing.

\section{Appendix}

Table 5 Definitions of the top-five signature character strengths (Peterson and Seligman 2004)

Character Definition

strength

Fairness Treating all people the same according to notions of fairness and justice; not letting personal feelings bias decisions about others; giving everyone a fair chance

Honesty [integrity, authenticity]: Speaking the truth but more broadly presenting oneself in a genuine way and acting in a sincere way; being without pretense; taking responsibility for one's feelings and actions

Judgment [open-mindedness, critical thinking]: Thinking things through and examining them from all sides; not jumping to conclusions; being able to change one's mind in light of evidence; weighing all evidence fairly

Kindness [generosity, nurturance, care, compassion, altruistic love, "niceness"]: Doing favors and good deeds for others; helping them; taking care of them

Love Valuing close relations with others, in particular those in which sharing and caring are reciprocated; being close to people 
Open Access This article is distributed under the terms of the Creative Commons Attribution 4.0 International License (http://creativecommons.org/licenses/by/4.0/), which permits unrestricted use, distribution, and reproduction in any medium, provided you give appropriate credit to the original author(s) and the source, provide a link to the Creative Commons license, and indicate if changes were made.

Publisher's Note Springer Nature remains neutral with regard to jurisdictional claims in published maps and institutional affiliations.

\section{References}

Allan, B. A., \& Duffy, R. D. (2014). Examining moderators of signature strengths use and wellbeing: Calling and signature strengths level. Journal of Happiness Studies, 15, 323-337. https://doi.org/10.1007/s10902013-9424-0.

Bakker, A. B., \& Demerouti, E. (2007). The job demands-resources model: State of the art. Journal of Managerial Psychology, 22, 309-328.

Buckingham, M., \& Clifton, D. O. (2001). Now, discover your strengths: How to develop your talents and those of the people you manage. London: Simon \& Schuster.

Buschor, C., Proyer, R. T., \& Ruch, W. (2013). Self- and peer-rated character strengths: How do they relate to satisfaction with life and orientations to happiness? Journal of Positive Psychology, 8, 116-127. https://doi.org/10.1080/17439760.2012.758305.

Büssing, A., \& Perrar, K.-M. (1992). Die Messung von Burnout: Untersuchung einer deutschen Fassung des Maslach Burnout Inventory (MBI-D) [The measurement of burnout: Investigating the German version of the Maslach Burnout Inventory (MBI-D)]. Diagnostica, 38(4), 328-353.

Canadian Medical Association. (2003). Guide to physician health and well-being: facts, advice and resources for Canadian doctors. Ottawa, ON: Canadian Medical Association.

Cohen, J. (1988). Statistical power analysis for the behavioral sciences. Hillsdale: Erlbaum.

Deci, E. L., \& Ryan, R. M. (2008). Hedonia, Eudaimonia, and well-being: An introduction. Journal of Happiness Studies, 9, 1-11. https://doi.org/10.1007/s10902-006-9018-1.

Diener, E. (1984). Subjective well-being. Psychological Bulletin, 95, 542-575.

Diener, E., Suh, E. M., Lucas, R. E., \& Smith, H. L. (1999). Subjective well-being: Three decades of Progress. Psychological Bulletin, 125(2), 276-302.

Douglass, R. P., \& Duffy, R. D. (2014). Strengths use and life satisfaction: A moderated mediation approach. Journal of Happiness Studies, 16, 619-632. https://doi.org/10.1007/s10902-014-9525-4.

Dyrbye, L. N., West, C. P., Satele, D., Boone, S., Tan, L., Sloan, J., \& Shanafelt, T. D. (2014). Burnout among U.S. medical students, residents, and early career physicians relative to the general U.S. population. Academic Medicine, 89, 443-451. https://doi.org/10.1097/ACM.0000000000000134.

Faul, F., Erdfelder, E., Buchner, A., \& Lang, A.-G. (2009). Statistical power analyses using G*power 3.1: Tests for correlation and regression analyses. Behavior Research Methods, 41(4), 1149-1160.

Gander, F., Proyer, R. T., Ruch, W., \& Wyss, T. (2012). The good character at work: An initial study on the contribution of character strengths in identifying healthy and unhealthy work-related behavior and experience patterns. International Archives of Occupational and Environmental Health, 85, 895-904. https://doi.org/10.1007/s00420-012-0736-x.

Gander, F., Proyer, R. T., Ruch, W., \& Wyss, T. (2013). Strength-based positive interventions: Further evidence for their potential in enhancing well-being and alleviating depression. Journal of Happiness Studies, 14, 1241-1259. https://doi.org/10.1007/s10902-012-9380-0.

Glaser, J., \& Seubert, C. (2014). Arbeitshandeln, Arbeitsbelastung, Arbeitsorganisation [Action, strain, and organization at work]. In P. Angerer, J. Glaser, H. Gündel, P. Henningsen, C. Lahmann, S. Letzel, \& D. Nowak (Eds.), Psychische und psychosomatische Gesundheit in der Arbeit. Wissenschaft, Erfahrungen, Lösungen aus Arbeitsmedizin, Arbeitspsychologie und Psychosomatischer Medizin [Mental and psychosomatic health at work. Science, experiences and solutions from occupational medicine, work psychology, and psychosomatic medizine] (pp. 47-63). Landsberg: Ecomed.

Glaser, J., Seubert, C., Hornung, S., \& Herbig, B. (2015). The impact of learning demands, work-related resources, and job stressors on creative performance and health. Journal of Personnel Psychology, 14, 3748. https://doi.org/10.1027/1866-5888/a000127.

Gold, K. J., Sen, A., \& Schwenk, T. L. (2013). Details on suicide among US physicians: Data from the National Violent Death Reporting System. General Hospital Psychiatry, 35(1), 45-49. 
Govindji, R., \& Linley, P. A. (2007). Strengths use, self-concordance and well-being: Implications for strengths coaching and coaching psychologists. International Coaching Psychology Review, 2, 143-153.

Harzer, C. (2016). The Eudaimonics of human strengths: The relations between character strengths and wellbeing. In J. Vittersø (Ed.), Handbook of Eudaimonic Well-Being, part of the international handbooks of quality-of-life series (pp. 307-322). Cham: Springer.

Harzer, C., \& Ruch, W. (2012). When the job is a calling: The role of applying one's signature strengths at work. The Journal of Positive Psychology, 7, 362-371. https://doi.org/10.1080/17439760.2012.702784.

Harzer, C., \& Ruch, W. (2013). The application of signature character strengths and positive experiences at work. Journal of Happiness Studies, 14, 965-983. https://doi.org/10.1007/s10902-012-9364-0.

Hausler, M., Huber, A., Strecker, C., Brenner, M., Höge, T., \& Höfer, S. (2017). Validierung eines Fragebogens zur umfassenden Operationalisierung von Wohlbefinden. Die deutsche version des comprehensive inventory of thriving (CIT) und die Kurzversion brief inventory of thriving (BIT) [validation of a holistic measure for the construct of well-being: The German version of the comprehensive inventory of thriving (CIT) and the short version brief inventory of thriving (BIT)]. Diagnostica, https://doi. org/10.1026/0012-1924/a000174.

Hausler, M., Strecker, C., Huber, A., Brenner, M., Höge, T., \& Höfer, S. (2017a). Distinguishing relational aspects of character strengths with subjective and psychological well-being. Frontiers in Psychology, 8. https://doi.org/10.3389/fpsyg.2017.01159.

Hausler, M., Strecker, C., Huber, A., Brenner, M., Höge, T., \& Höfer, S. (2017b). Associations between the application of signature character strengths, health and well-being of health professionals. Frontiers in Psychology, 8. https://doi.org/10.3389/fpsyg.2017.01307.

Heinke, W., Dunkel, P., Brähler, E., Nübling, M., Riedel-Heller, S., \& Kaisers, U. X. (2011). Burnout in anesthesiology and intensive care: Is there a problem in Germany? Der Anaesthesist, 60(12), 1109-1118.

Höfer, S., Hausler, M., Huber, A., Strecker, C., Renn, D., \& Höge, T. (2018). Psychometric characteristics of the German Values in Action Inventory of Strengths 120-item Short Form. Applied Research in Quality of Life. https://doi.org/10.1007/s11482-018-9696-y.

Höge, T., Strecker, C., Hausler, M., Huber, A., \& Höfer, S. (2018). Perceived Socio-moral Climate and the Applicability of Signature Character Strengths at Work: A Study among Hospital Physicians. Applied Research in Quality of Life. https://doi.org/10.1007/s11482-018-9697-x.

Huber, A., Webb, D., \& Höfer, S. (2017). The German version of the strengths use scale: The relation of using individual strengths and well-being. Frontiers in Psychology, 8. https://doi.org/10.3389 /fpsyg.2017.00637.

IBM Corp. (2015). IBM SPSS Statistics for Windows, Version 24.0. Armonk, New York: IBM Corp.

Landrigan, C. P., Rothschild, J. M., Cronin, J. W., Kaushal, R., Burdick, E., Katz, J. T., Lilly, C. M., Stone, P. H., Lockley, S. W., Bates, D. W., \& Czeisler, C. A. (2004). Effect of reducing interns' work hours on serious medical errors in intensive care units. The New England Journal of Medicine, 351, 1838-1848.

Lavy, S., \& Littman-Ovadia, H. (2017). My better self: Using strengths at work and work productivity, organizational citizenship behaviour, and Satisfaction. Journal of Career Development, 44(2), 95-109.

Leiter, M. P., \& Maslach, C. (2016). Latent burnout profiles: A new approach to understanding the burnout experience. Burnout Research, 3, 89-100. https://doi.org/10.1016/j.burn.2016.09.001.

Linley, P. A., \& Harrington, S. (2006). Strengths coaching: A potential-guided approach to coaching psychology. International Coaching Psychology Review, 1, 37-46.

Linley, P. A., Nielsen, K. M., Gillett, R., \& Biswas-Diener, R. (2010). Using signature strengths in pursuit of goals: Effects on goal progress, need satisfaction, and well-being, and implications for coaching psychologists. International Coaching Psychology Review, 5, 6-15.

Littman-Ovadia, H. (2015). Short form of the VIA survey: Construction of scales and preliminary tests of reliability and validity. International Journal of Humanities Social Sciences and Education, 2(4), 229237.

Littman-Ovadia, H., \& Lavy, S. (2016). Going the extra mile: Perseverance as a key character strength at work. Journal of Career Assessment, 24, 240-252. https://doi.org/10.1177/1069072715580322.

Littman-Ovadia, H., \& Steger, M. F. (2010). Character strengths and well-being among volunteers and employees: Toward an integrative model. The Journal of Positive Psychology, 5, 419-430. https://doi. org/10.1080/17439760.2010.516765.

Littman-Ovadia, H., Lavy, S., \& Boiman-Meshita, M. (2017). When theory and research collide: Examining correlates of signature strengths use at work. Journal of Happiness Studies, 18, 527-548. https://doi. org/10.1007/s10902-016-9739-8.

Lockley, S. W., Cronin, J. W., Evans, E. E., Cade, B. E., \& Lee, C. J. (2004). Landrigan, C.P., et al. for the Harvard work hours, health and safety group (2004). Effect of reducing interns' weekly work hours on sleep and attentional failures. The New England Journal of Medicine, 351, 1829-1837. 
Lyubomirsky, S., King, L., \& Diener, E. (2005). The benefits of frequent positive affect: Does happiness lead to success? Psychological Bulletin, 131, 803-855. https://doi.org/10.1037/0033-2909.131.6.803.

Maslach, C., Schaufeli, W. B., \& Leiter, M. P. (2001). Job burnout. Annual Review of Psychology, 52, 397422. https://doi.org/10.1146/annurev.psych.52.1.397.

Ouweneel, E., Le Blanc, P. M., \& Schaufeli, W. B. (2014). On being grateful and kind: Results of two randomized controlled trials on study-related emotions and academic engagement. Journal of Psychology, 148, 37-60. https://doi.org/10.1080/00223980.2012.742854.

Park, N., Peterson, C., \& Seligman, M. E. P. (2004). Strengths of character and well-being. Journal of Social and Clinical Psychology, 23, 603-619.

Peterson, R. (1994). A meta-analysis of Cronbach's coefficient alpha. Journal of Consumer Research, 21, 381-391.

Peterson, C. (2006). A primer in positive psychology. Oxford: Oxford University Press.

Peterson, C., \& Park, N. (2006). Character strengths in organizations. Journal of Organizational Behavior, 27, 1149-1154. https://doi.org/10.1002/job.398.

Peterson, C., \& Park, N. (2009). Classifying and measuring strengths of character. In S. J. Lopez \& C. R. Snyder (Eds.), Oxford handbook of positive psychology (2nd ed., pp. 25-33). New York: Oxford University Press.

Peterson, C., \& Park, N. (2011). Character strengths and virtues: Their role in wellbeing. In S. I. Donaldson, M. Csikszentmihalyi, \& J. Nakamura (Eds.), Applied positive psychology: Improving everyday life, health, schools, work, and society (pp. 49-62). New York: Routledge/ Taylor \& Francis Group.

Peterson, C., \& Seligman, M. E. P. (2004). Character strengths and virtues: A handbook and classification. New York: Oxford University Press.

Peterson, C., Ruch, W., Beermann, U., Park, N., \& Seligman, M. E. P. (2007). Strengths of character, orientations to happiness and life satisfaction. The Journal of Positive Psychology, 2, 149-156. https://doi.org/10.1080/17439760701228938.

Pircher Verdorfer, A., Weber, W. G., Unterrainer, C., \& Seyr, S. (2012). The relationship between organizational democracy and socio-moral climate: Exploring effects of the ethical context in organizations. Economic and Industrial Democracy, 34, 423-449. https://doi.org/10.1177/0143831X12450054.

Proctor, C. L., Maltby, J., \& Linley, P. A. (2011). Strengths use as a predictor of well-being and health-related quality of life. Journal of Happiness Studies, 12, 153-169. https://doi.org/10.1007/s10902-009-9181-2.

Proyer, R. T., Wellenzohn, S., Gander, F., \& Ruch, W. (2014). Toward a better understanding of what makes positive psychology interventions work: Predicting happiness and depression from the person $\times$ intervention fit in a follow-up after 3.5 years. Applied Psychology: Health and Well-Being, 7, 108-128. https://doi.org/10.1111/aphw.12039.

Rath, T. (2007). StrengthsFinder 2.0. New York, NY: Gallup Press.

Ring, L., Höfer, S., McGee, H., Hickey, A., \& O'Boyle, C. (2007). Individual quality of life: Can it be accounted for by psychological or subjective well-being? Social Indicators Research, 82, 443-461. https://doi.org/10.1007/s11205-006-9041-y.

Saucier, G., Bel-Bahar, T., \& Fernandez, C. (2007). What modifies the expression of personality tendencies? Defining basic domains of situation variables. Journal of Personality, 75, 479-504. https://doi. org/10.1111/j.1467-6494.2007.00446.x.

Schaufeli, W.B., \& Bakker, A.B. (2003). Test manual for the Utrecht Work Engagement Scale. Unpublished manuscript. Utrecht University, Netherlands. http://www.schaufeli.com. Accessed 11 January 2018.

Schaufeli, W. B., Salanova, M., González-Romá, V., \& Bakker, A. B. (2002). The measurement of engagement and burnout: A two sample confirmatory factor analytic approach. Journal of Happiness Studies, 3, 71-92.

Schaufeli, W. B., Bakker, A. B., \& Salanova, M. (2006). The measurement of work engagement with a short questionnaire: A cross-national study. Educational and Psychological Measurement, 66, 701-716. https://doi.org/10.1177/0013164405282471.

Schaufeli, W. B., Leiter, M. P., \& Maslach, C. (2009). Burnout: 35 years of research and practice. Career Development International, 14, 204-220. https://doi.org/10.1108/13620430910966406.

Schwarz, N., \& Strack, F. (1999). Reports of subjective well-being. Judgmental processes and their methodological implications. In D. Kahneman, E. Diener, \& N. Schwarz (Eds.), Well-being. The foundations of hedonic psychology (pp. 61-84). New York: Russell Sage Foundation.

Seligman, M. (2011). Flourish: A visionary new understanding of happiness and wellbeing. New York, NY US: Free Press.

Seligman, M. E. P., \& Csikszentmihalyi, M. (2000). Positive psychology: An introduction. American Psychologist, 55, 5-14. https://doi.org/10.1037//0003-066X.55.1.5. 
Seligman, M. E. P., Steen, T. A., Park, N., \& Peterson, C. (2005). Positive psychology progress: Empirical validation of interventions. American Psychologist, 60, 410-421. https://doi.org/10.1037/0003-066 X.60.5.410.

Shirom, A., Melamed, S., Toker, S., Berliner, S., \& Shapira, I. (2005). Burnout and health review: Current knowledge and future research directions. International Review of Industrial and Organizational Psychology, 20, 269-307.

Strecker, C., Huber, A., Höge, T., Hausler, M., \& Höfer, S. (2018). Identifying thriving workplaces in hospitals: Work characteristics and the applicability of character strengths at work. Applied Research in Quality of Life. https://doi.org/10.1007/s11482-018-9693-1.

Su, R., Tay, L., \& Diener, E. (2014). The development and validation of the comprehensive inventory of thriving (CIT) and the brief inventory of thriving (BIT). Applied Psychology: Health \& Well-Being, 6, 251-279. https://doi.org/10.1111/aphw.12027.

VIA Institute on Character. (2014). VIA-120 Survey. http://www.viacharacter.org/www/VIA-Assessments1. Accessed 5 April 2018.

Wallace, J. E., Lemaire, J. B., \& Ghali, W. A. (2009). Physician wellness: A missing quality indicator. Lancet, 374, 1714-1721. https://doi.org/10.1016/S0140-6736(09)61424-0.

Weber, W. G., Unterrainer, C., \& Höge, T. (2008). Sociomoral atmosphere and prosocial and democratic value orientations in enterprises with different levels of structurally anchored participation. German Journal of Human Ressource Management: Zeitschrift für Personalforschung, 22, 171-194. https://doi.org/10.1177 $/ 239700220802200205$.

Weigl, M., Müller, A., Vincent, C., Angerer, P., \& Sevdalis, N. (2012). The association of workflow interruptions and hospital doctors' workload: A prospective observational study. BMJ Quality \& Safety, 21, 399-407. https://doi.org/10.1136/bmjqs-2011-000188.

Wurm, W., Vogel, K., Holl, A., Ebner, C., Bayer, D., Mörkl, S., Szilagyi, I. S., Hotter, E., Kapfhammer, H. P., \& Hofmann, P. (2016). Depression-burnout overlap in physicians. PLoS One, 11, e0149913. https://doi. org/10.1371/journal.pone.0149913.

\section{Affiliations}

\section{Alexandra Huber ${ }^{1}$. Cornelia Strecker ${ }^{2}$ - Melanie Hausler ${ }^{1} \cdot$ Timo Kachel $^{2}$. Thomas Höge ${ }^{2}$. Stefan Höfer ${ }^{1}$}

Alexandra Huber

alexandra.huber@i-med.ac.at

1 Department of Medical Psychology, Medical University of Innsbruck, Innsbruck, Austria

2 Institute of Psychology, University of Innsbruck, Innsbruck, Austria 